\title{
Design of clinched joints on the basis of binding mechanisms
}

\author{
Jan Kalich $^{1} \cdot$ Uwe Füssel ${ }^{1}$ \\ Received: 14 October 2021 / Accepted: 10 January 2022 / Published online: 4 February 2022 \\ (c) The Author(s) 2022
}

\begin{abstract}
The work carried out is based on the thesis properties of clinched joints are determined by the proportions of binding mechanisms form-closure, force-closure and material-closure. To describe the acting binding mechanisms and thus to derive the joint properties, detailed knowledge of the local effect of the individual binding mechanisms is necessary to ensure their targeted adjustment by the joining process. The targeted setting of different proportions of the binding mechanisms is achieved firstly via tool geometry and secondly via surface condition of the joined parts. An introduced form-closure component can be quantified by metallographic cross section with subsequent measurement of the quality-determining parameters such as undercut, penetration depth and neck thickness. To qualify the force-closure component, a torsional load can be applied mechanically at rotationally symmetrical clinch joints. This also allows the influence of different surface conditions on the tribological system to be quantified. Measurement of electrical resistance can reveal the binding mechanisms of force- and material-closure. These investigations are carried out on an aluminum joining part combination of the same type. As a result of these investigations, the clinched joints can be designed according to the load occurring in the later life cycle in the form of an optimum and compromise variant with regard to minimum loads to be transmitted mechanically, electrically with regard to low resistance or manufacturing with minimum energy input.
\end{abstract}

Keywords Clinching $\cdot$ Aluminum $\cdot$ Tool geometry $\cdot$ Surface condition $\cdot$ Binding mechanism

\section{Introduction}

Weight reduction through lightweight construction is not only considered in automotive engineering as an essential approach to meet the growing demand for a reduction in energy consumption. In the future, the manufacturing process must also be designed with energy consumption, sustainability and resource conservation in mind. To achieve these goals, transformable joining processes in versatile process chains are necessary. Thus, the successful use of material combinations depends to a large extent on joining technology, and comprehensive knowledge of joining processes is of crucial importance. As a joining by forming process, clinching offers the advantage of energy-reduced joining of a wide range of materials. Clinching represents as an established joining technique for sheet metals and profiled parts and is "state of the art" in automotive construction when

Jan Kalich

jan.kalich@tu-dresden.de

1 Chair of Joining Technology and Assembly, Technische

Universität Dresden, 01062 Dresden, Germany mechanical properties and corrosion behavior are considered exclusively. The increasing range of applications covers also joining tasks at e-mobility [1] to contact electrical conductors e.g. battery systems [2], busbars or fuses.

The motivation of the work is description of the binding mechanisms and derivation of joint properties (mechanical, electrical, thermal). Furthermore, in the determination of manufacturing parameters based on the binding mechanisms primarily required for the load by detailed knowledge of the effect of the individual binding mechanisms. In conclusion of the work carried out, a targeted control and utilization of the binding mechanisms generated by the joining process is to be carried out to improve the required properties of the clinched joint.

Clinched joints are designed according to geometric features such as neck thickness $t_{n}$ and undercut $f$ [3]. These values correlate with the non-destructively measurable quality criterion of bottom thickness $t_{b}$ if the tool geometries are known [4]. Clinched joints are based on the binding mechanisms form- and force-closure as shown by Groche in [5] and Salamati in [6]. The focus here is on the form-closure 
component. The force-closure component is mentioned in these two publications, but is not discussed further.

At clinched joints, the form-closure component is defined by undercut and penetration depth. The force closure is determined by the existing surface pressure between components to be joined. A material-closure component arising in clinched aluminum materials, as demonstrated in [7] for A199.5 and in [8] for Aluminum alloys, is not addressed. A material closure between the joining partners is based on the formation of a bond, in this case a metal bond. A quantification of these three components is not considered.

Clinched joints can be designed in optimum or compromise versions according to known load paths or manufacturing capabilities. The tool geometries used influence the local and inhomogeneously distributed shape changes as Tenario shows in [9] by using a clinched joint with closed die of a $10 \mathrm{~mm}$ diameter. In addition to the tool geometries, the process parameters [10] and the surface conditions [11] of the joined parts also influence the inhomogeneous shape changes at the clinch joint. A Finite Elements Simulation to represent the residual strain within a clinch joint with a nominal diameter of $8 \mathrm{~mm}$ and closed die is shown in Fig. 1a [12]. Due to the non-homogeneous forming in clinch joint production, the work hardening of the parts to be joined differs depending on the area (punch entry, neck area, undercut area and bottom area) (Fig. 1a). The inhomogeneously distributed shape changes cause inhomogeneously distributed stresses and surface pressures (Fig. 1b) between the joining partners [13]. In [13], Steinfelder shows the locally resolved, inhomogeneous force-closure component in the form of contact normal force due to a variation of tool geometry by means of a Finite Elements Simulation of the surface pressure between joining partners made of HCT590X (Fig. 1b).

Abe performs in [14] Finite Elements Simulations of the respective shape changes on the basis of aluminum and mild steel combinations and verifies this with experimental investigations. The degree of strain hardening and the geometric dimension of the individual areas determine the property profile of the joint as a function of the subsequent load case.

In [15], analyzes Lee pure aluminum joints of the alloys Al5052 and Al6063 with regard to the influence of varying geometrical parameters on the strength and failure behavior of the clinched joints. Analytical relationships of the geometrical dimensions among themselves on the failure behavior are presented. Gibmeier [16] compares under assistance of X-ray and neutron diffraction the difference between expandable and closed dies with respect to the residual stress state.

Depending on the known loads on the joint in the subsequent life cycle, the tool geometries used, the system parameters such as clamping force, the components to be joined and their surface properties, different proportions of the binding mechanisms form-, force- and material-closure are formed. In order to use clinched connections optimally, it is necessary to design the clinched joints according to the respective requirements. Both basic production-related parameters and application-related loads must be considered as influencing variables. In the case of mechanically stressed joints, the primary binding mechanisms are form- and forceclosure. Whereas in the case of a joint that is predominantly subject to electrical stress, the binding mechanism of forceclosure, extended by a material-closure component, can reduce the electrical resistance and as a consequence the thermal load. Mechanical optimization of the joint is usually based on the adjustment of geometric parameters. When optimizing the joint for electrical applications, the advantages inherent in the process, such as surface enlargement and relative movement of the joining partners, can used specifically to generate metallic and quasi-metallic micro-contacts. This gives the opportunity to design clinched joints on the basis of the necessary or dominant load for the respective application and to exploit the binding mechanisms forceclosure and material-closure to improve the joint properties.

\section{Design of joints}

\subsection{Methods}

For the description of the acting binding mechanisms and, consequently, the derivation of the joint properties, a detailed knowledge of the local effect of the individual binding mechanisms is necessary to ensure their targeted control by the joining process. An introduced form-closure component can
Fig. 1 Distribution of residual strain (a) [12] and contact force (b) [13] at the joint (a)

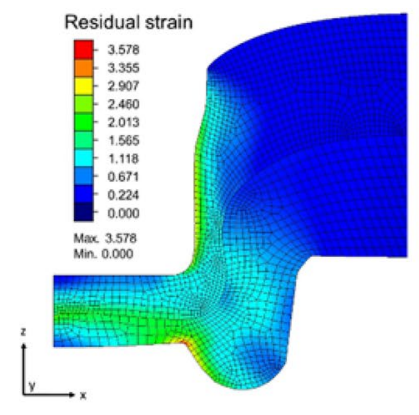

(b)

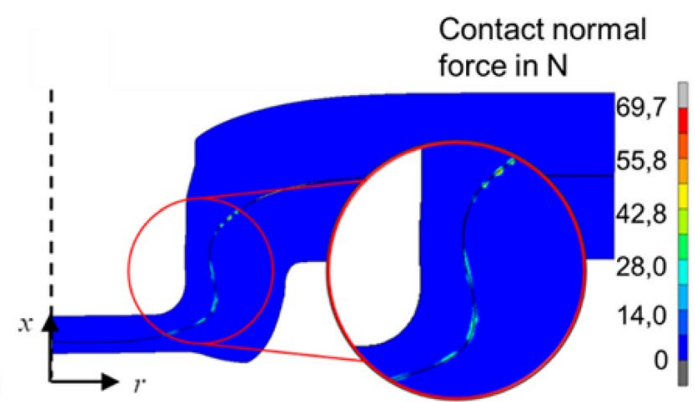


be qualified and quantified via metallographic cross-sections with subsequent measurement of the quality parameters. For the qualification of a force-closure component, a torsional load can be applied to rotationally symmetrical clinch joints [4]. This can also be used to distinguish the effect of different surface conditions on the tribological system. Resistance measurement in the form of the four-wire method or Kelvin method can be used to prove the binding mechanisms force- and material-closure. The resulting form-closure component is dependent on the direction of loading. The force-closure component and material-closure component are independent of the direction of loading. These testing methods where introduced and qualified in [17] to detect the change of force-closure component within the process chain by using an aluminum steel mixed compound due to precipitation hardening of the aluminum alloy EN AW 6014.

\subsection{Tool selection}

An example of the design of clinched joints (single-stage, round joint without cutting portion, closed die) is used to illustrate the effect of different proportions of binding mechanisms on the joining partner combination EN AW $6014, t=2.0 \mathrm{~mm}$. The aluminum alloy was delivered and joined at the heat treatment condition T4. After delivery, the aluminum was stored at a temperature of minus $22{ }^{\circ} \mathrm{C}$ until further processing. This step is necessary to maintain the condition T4. Figure 2a shows series 1 as the starting point for the investigations. The geometrical design of the clinch joints was carried out using a cylindrical punch with a diameter of $4.6 \mathrm{~mm}$ and a die with a diameter of $8.0 \mathrm{~mm}$ and a depth of $1.4 \mathrm{~mm}$.

In series 2 , the clinched joints were joined using an alternative tool set. Here a conical punch with an enlarged diameter of $4.8 \mathrm{~mm}$ and the same die are used. Due to the larger diameter and thus a larger punch volume, an increase of the bottom thickness is necessary to achieve the comparable dimensions (Fig. 2b) for neck thickness and undercut.
Although these different punch geometries lead to identical values for neck thickness and undercut, cf. Fig. 2, and thus to a comparable form-closure component, the variation of the punch geometry results in a different force-closure component.

Another way of influencing the force-closure component is the surface condition of the joining partners. Series 3 is used as a comparison for this purpose. The changed surface condition is adjusted by cleaning with isopropanol. This cleaning eliminates surface contamination for example due to storage and handling effects and does not affect the aluminum oxide layer, described in Altenpohl [18]. The clinched joint (Fig. 2c), produced under these conditions, has a smaller undercut due to the larger friction between the joining partners, with the same neck and bottom thickness as series 2. Compared to the two series, the annular channel of the die is not completely filled in series 3 . Furthermore, the proportions of the joining partners in the total bottom thickness also vary.

During the clinching processes, force-displacementcurves (Fig. 3) were recorded. For the quantification of the introduced energy, the recording of the complete process graph including the return stroke is necessary. In order to record the total work introduced, the force is measured under the die. The measured force represents the force applied by the drive unit, which is counteracted by the blank-holder force.

The joining process starts when the blank-holder contacts the joining partner on the punch side (Fig. 3, step 1) and the blank-holder force is built up. Then the clinching punch is placed on the joining partners (step 2) and elastic deformation begins. Step 3 begins with the elastic-plastic deformation and is completed with the contact of the dieside joining partner with the anvil of the die. With further penetration of the punch tool, the component thickness is reduced and a radial material flow is initiated. Due to the different punch geometries, significant differences in the force-displacement-curves can be observed from step
Fig. 2 Metallographic crosssections of Series 1 Cylindrical punch (a), Series 2 Conical punch (b), Series 3 Conical punch and cleaned surface (c)

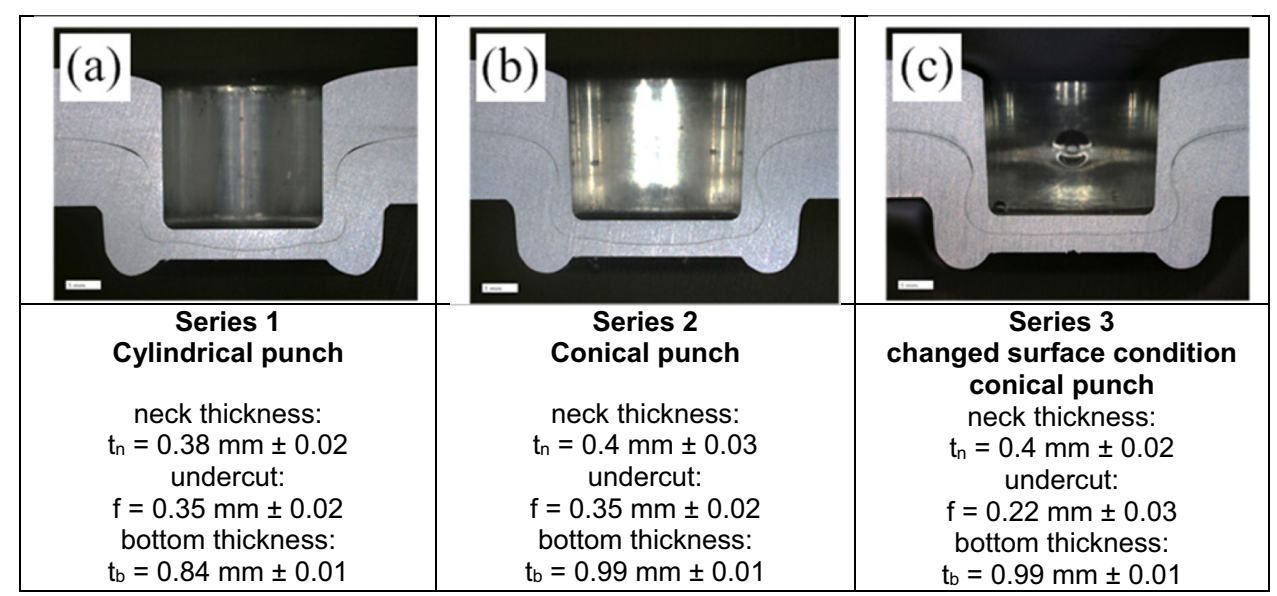


Fig. 3 Comparison of the forcedisplacement-curves at the joining process

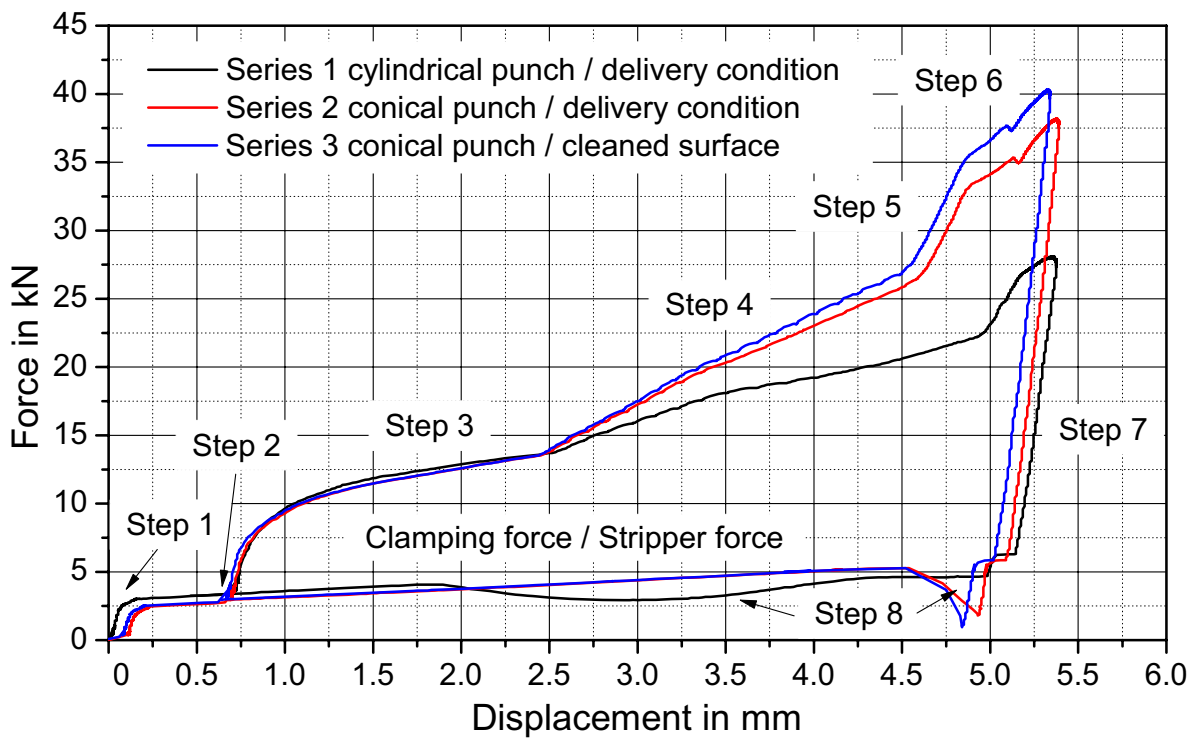

4 onwards. Due to the smaller punch diameter of series 1 , compared to series 2 , a smaller volume of material is formed, which results in a lower process force. The process graph of series 3 shows a slightly wavy course in this area, which is due to the increased friction between the components and between the components and the punch due to adhesion and sliding conditions. At the transition from step 4 to step 5, the contact area between the dieside component and the die wall is increased, which is accompanied by additional friction and is reflected in the curve as a larger increase. The subsequent flatter increase in step 6 is due to the free forming of the die-side component until the annular channel is completely formed. Step 6 ends when the target bottom thickness is reached. The return stroke (step 7) is then initiated. The blank-holder now assumes the function of a stripper for demolding the punches from the cup of the clinched joint. In step 8, the punch is pulled out of the cup. In series 1 , demolding takes place over a longer distance, since here the cylindrical punch is pulled out over the entire penetration depth as a result of the hole groove. When the return stroke distance of $2 \mathrm{~mm}$ is reached, the punch is completely pulled out of the cup. The noticeable significant force drop on the process curves of series 2 and 3 is due to the abrupt removal of the conical punch from the cup of the clinched joint. In the process curves of all three series, a linear force drop corresponding to the spring characteristic of the blank-holder sets after the punch has been demolded. The force-displacement-curves of series 2 and 3 differ from step 4 due to the different surface conditions. This surface preparation results in a higher force and work requirement when forming the clinched joint.

The work $W_{C l}$ required to produce a clinch joint, when clinching with linear punch movement, can be described as the integral of the joining force over the punch stroke (Eq. 1).

$W_{C l}=\int F(s) d s$

This calculation results in the values listed in Table 1 for the work required to generate the clinched joints. The forming work represents the work requirement for the pure elastic-plastic deformation. This is represented by the area enclosed in Fig. 3. The total work represents the sum of the forming work and the required blank-holder work.

After joining the samples, a precipitation hardening of the aluminum alloy takes place according to the condition (185 ${ }^{\circ} \mathrm{C}$ for $20 \mathrm{~min}$ ) of the manufacturer [19].
Table 1 Work required for a clinched joint

\begin{tabular}{llll}
\hline $\mathrm{W}_{\mathrm{Cl}}$ in Joule & $\begin{array}{l}\text { Series 1 cylindrical punch/ } \\
\text { delivery condition }\end{array}$ & $\begin{array}{l}\text { Series 2 conical punch/ } \\
\text { delivery condition }\end{array}$ & $\begin{array}{l}\text { Series 3 conical } \\
\text { punch/cleaned } \\
\text { surface }\end{array}$ \\
\hline Forming work & $56.33 \pm 1.81$ & $65.55 \pm 0.25$ & $66.58 \pm 0.30$ \\
Blank-holder work & $18.19 \pm 0.47$ & $18.99 \pm 0.23$ & $19.00 \pm 0.18$ \\
Total work & $74.53 \pm 2.28$ & $84.54 \pm 0.48$ & $85.58 \pm 0.13$ \\
\hline
\end{tabular}




\subsection{Mechanical test}

\subsubsection{Quasi-static shear load test}

For the quasi-static test under shear load, single-cut overlapped specimens were manufactured in accordance with DIN EN ISO 14273 [20]. The specimen geometry and overlap length used meet the requirements of [3]. After clamping the specimens in a Zwick Z030 tensile testing machine, the test load was applied at a rate of $5 \mathrm{~mm} / \mathrm{min}$ until failure of the specimens.

\subsubsection{Torsion test}

After clinching, the residual stress state is free of load. In order to detect the force-closure component, this geometrically rotationally symmetrical clinched joint is subjected to a torsional load. First, the force-closure component is loaded in addition to the elastic deformation of the joining partners. The mechanical stress in the area of the real contact surface in the neck, undercut and bottom areas increases until the static friction between the joining partners is overcome. Shear stress occurs in the circular cross-sectional area of the neck. The roughness peaks of the surfaces in contact represent a theoretic form-closure, which is, however, difficult to verify.
To carry out the torsion tests, a test rig (Fig. 4) with a EC tightening spindle with a maximum torque of $30 \mathrm{Nm}$ was adapted to the requirements of the torsion test of clinched joints. The measured values documented were the applied torque in the EC tightening spindle and via an external torque angle encoder with a resolution of $0.25^{\circ}$. The specimen geometry and arrangement were taken from [4].

Figure 5a shows the characteristic failure curve. The failure case consists of a twisting of the joined components relative to each other (Fig. 5b). The maximum value indicates the testing torque.

\subsection{Electrical test}

The performance of mechanical tests allows the detection of a force-closure component. However, it is not possible to determine the presence of a material-closure component. To test the presence of this third binding mechanism and to verify the mechanical test results of the twisting test, a further independent measured variable is to be used. A clinched connection also represents an electrical contact in the form of a non-separable connection [21]. If two conductors are joined, spot, line or areal contacts are created [22]. Due to impurity layers (e.g. oxides or other contaminates), electrical contacting only occurs at spots where the impurity layers are broken through, referred
Fig. 4 Test setup torsion test rig [13]

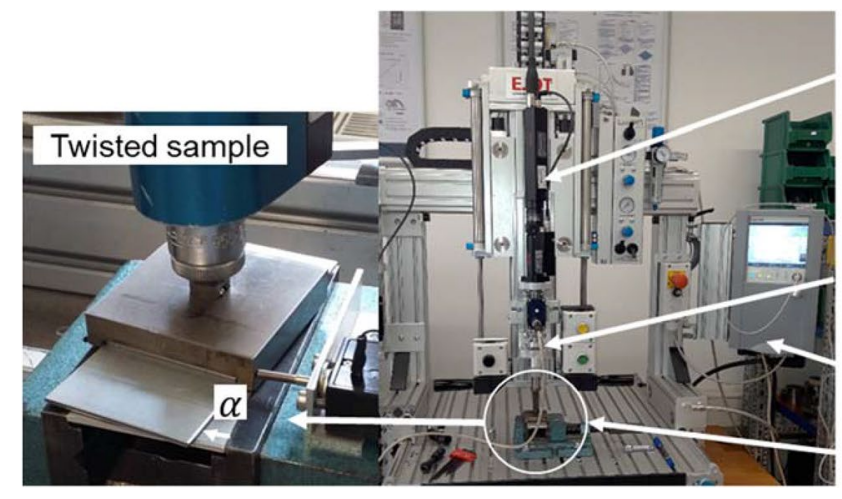

Tightening spindle with torque - angle of rotation detection

External torque angle of rotation detection

Process monitor

Test sample
Fig. 5 Characteristic test curve after torsion test (a) occurring failure mode (b)

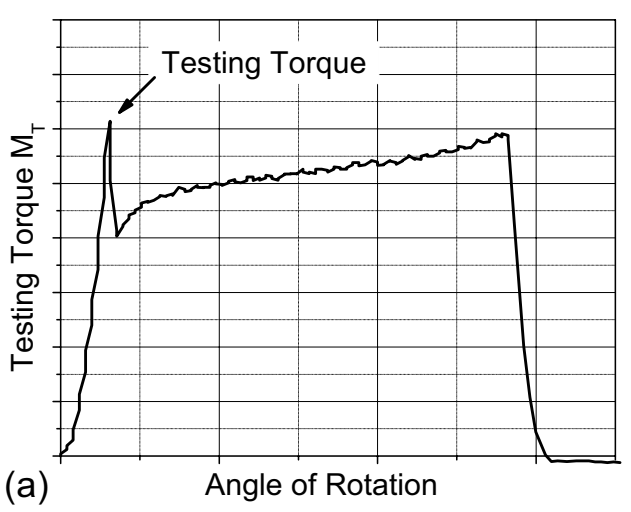

Failure case: Torsion

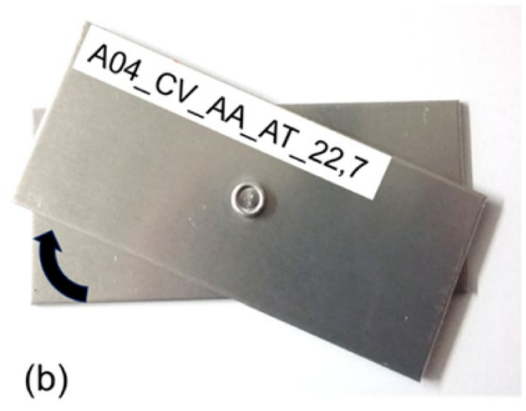


in [23]. The resulting true metallic contact areas, the micro-contacts ( $\alpha$-spots), conduct the major part of the current. In addition to the true metallic contact areas, part of the current also flows through very thin impurity layers, which allow the electrons to tunnel through. According to Holm [24], these areas are called quasi-metallic contact areas, see also [21]. The current lines constrict in the micro-contacts. The so-called constriction points generate the constriction resistance, which can hardly be calculated even if the position, number and size of the micro-contacts are known. The decisive resistance for contacting, the contact resistance $R_{K}$ (Eq. 2), is composed of the constriction resistance $R_{E}$ and, if an intact impurity layer is present, the impurity layer resistance $R_{F}$.

$R_{K}=R_{E}+R_{F}$

According to [21], the constriction resistance in Eq. (3) is determined via the relation:

$R_{E}=\rho \sqrt{\frac{\pi}{4}} \cdot \frac{H}{F_{K}}$

The constriction resistance is described by the specific resistance of the materials involved $\rho$, the material hardness $H$ and the contact force $F_{K}$. These dependencies are also represented in [25] by Zhai. This contact force between the two connected conductors represents the force-closure component with respect to a clinched joint, see also [13]. The specific resistance of the components is still constant until the precipitation hardening process takes place. After the precipitation hardening process, the specific resistance of the components degreases. Zhang presents this effect in [26] at an Al-Mg-Si Alloy and a measurement in [17] at a homogenous conductor of the investigated aluminum alloy EN AW 6014.

The hardness at the homogeneous conductor is, caused by the precipitation hardening process increasing from $66.5 \pm 0.8$ HB5 to $96.1 \pm 0.8$ HB5 [4]. That means a harder surface can realize a higher surface pressure between the joining partners. Therefore the constriction resistance will be degreasing. In superposition with these effects the contact force will also be degreasing, so the force-closure component will be reduced. If the forceclosure component is reduced, the electrical resistance of the joint increases.

For measuring the electrical resistance of a clinched joint using the four-wire method or Kelvin method, also shown by Jiang in [27]. The LoRe II micro-ohmmeter, has a measuring range of $10 \mathrm{n} \Omega$ to $1.5 \Omega$ with a resolution of $1 \mathrm{n} \Omega$, was used for the electrical resistance measurement. For each measurement, the micro-ohmmeter outputs also a measurement uncertainty.

\section{Experimental results}

\subsection{Mechanical results}

The results of the quasi-static shear tensile tests performed are shown in Fig. 6. During loading of the specimens, the force-displacement-curves were recorded. For all specimens tested, failure due to neck break occurs in combination with a small deformation of the cup in the undercut and bottom regions.

The influence of the different punch geometry is expressed not only in the transmissible force but also in the work performed. The specimens of series 1 reach their maximum force at $1.63 \mathrm{kN}$, whereas the specimens of series 2 exhibit a maximum force of $1.85 \mathrm{kN}$. Also, the work absorption to fracture for series 2 is $31 \%$ higher than that of series 1 , which is associated with the increased work applied during the joining process the series 2 (Table 1). Series 3 specimens show a qualitatively similar behavior under shear tensile loading. The differences with series 1 and 2 are manifested in a larger maximum force $F_{\max }$. However, the work capacity is $10 \%$ lower compared to series 2 due to the smaller deformation path. This is due to a smaller deformation of the cup of the component on the punch-side as a result of the increased friction and the associated forceclosure component between the joining partners.

In addition to the quasi-static shear test, the series were subjected to a torsional load in order to show the different proportions of the binding mechanism of the force-closure component depending on the tools, used and the surface condition (Fig. 7).

Failure case "torsion" (Fig. 5b) occurs in all tested specimens. A comparison of the testing torques achieved shows that the specimens of series 2 have a higher testing torque

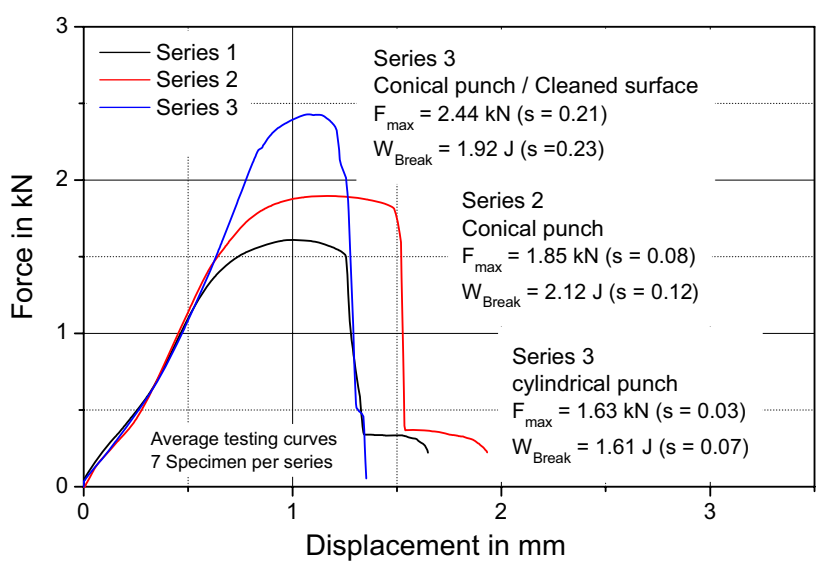

Fig. 6 Comparison quasi-static shear load depending on the punch geometry and surface condition 


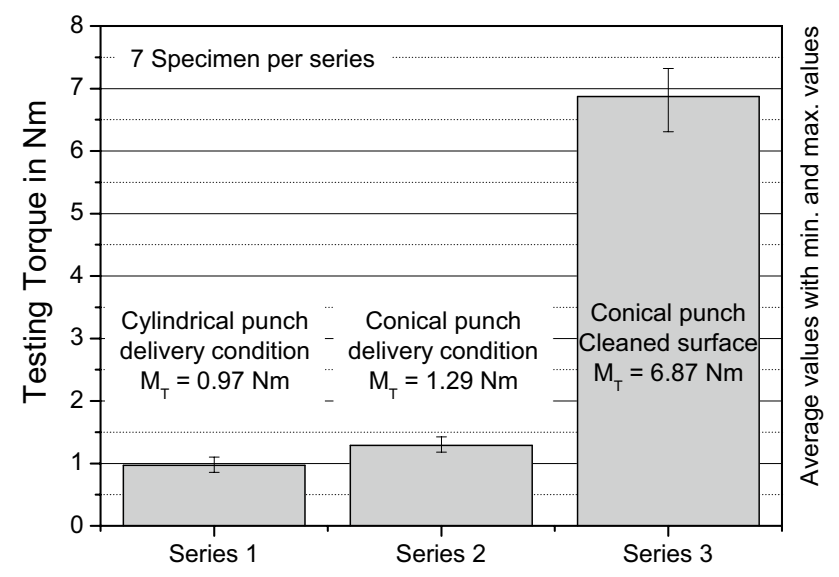

Fig. 7 Testing-torque depending on the punch geometry and surface condition

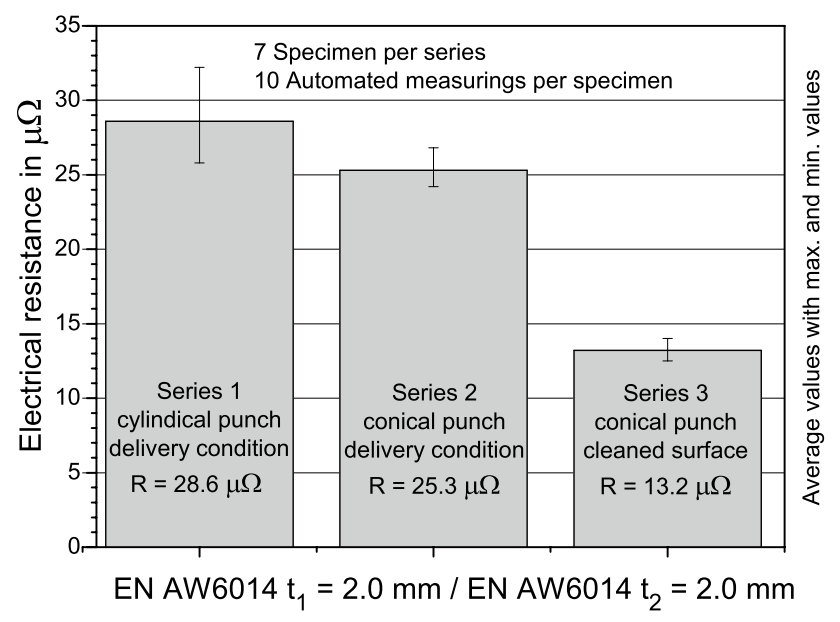

Fig. 8 Electrical resistance in correlation to tool geometry and surface condition than series 1 . This means that there is a greater surface pressure and therefore a greater proportion of force-closure between the series 2 parts in the clinch area.

In addition to the joining tools, the surface condition of the components is the dominant factor influencing the binding mechanisms to be generated and the resulting property profile of the clinched joints. If the same tools are used but the surface condition is changed, the transmissible torsional moment can be significantly increased by a factor of 5 (Fig. 7). This means that the increased friction between the joining partners causes an increased force-closure component.

\subsection{Electrical results}

The results of the electrical test are shown in Fig. 8. It can be seen that firstly the tool selection has an influence on the measured electrical resistance. A comparison of series 1 and 2 shows a $12 \%$ reduction in electrical resistance. This means that series 2 has an increased current carrying capacity. The increased force-closure component introduced via the setting process causes this effect. This increased force-closure component at the clinching joint is accompanied not only by a higher joining force but also by an increased energy input (Table 1).

Series 3 shows a significantly reduced electrical resistance (Fig. 8). Compared to series 2, which was joined with the identical tools, the cleaned surface has the effect of reducing the electrical resistance of $48 \%$. However, due to the cleaned surface and the resulting increase in friction during the joining process, the energy input to the clinched joint is increased by only $1 \%$ compared to series 2 (Table 1 ). The improved electrical conductivity is caused by metallic micro-contacts (Fig. 9), the number and size of which, however, cannot be directly influenced [24].
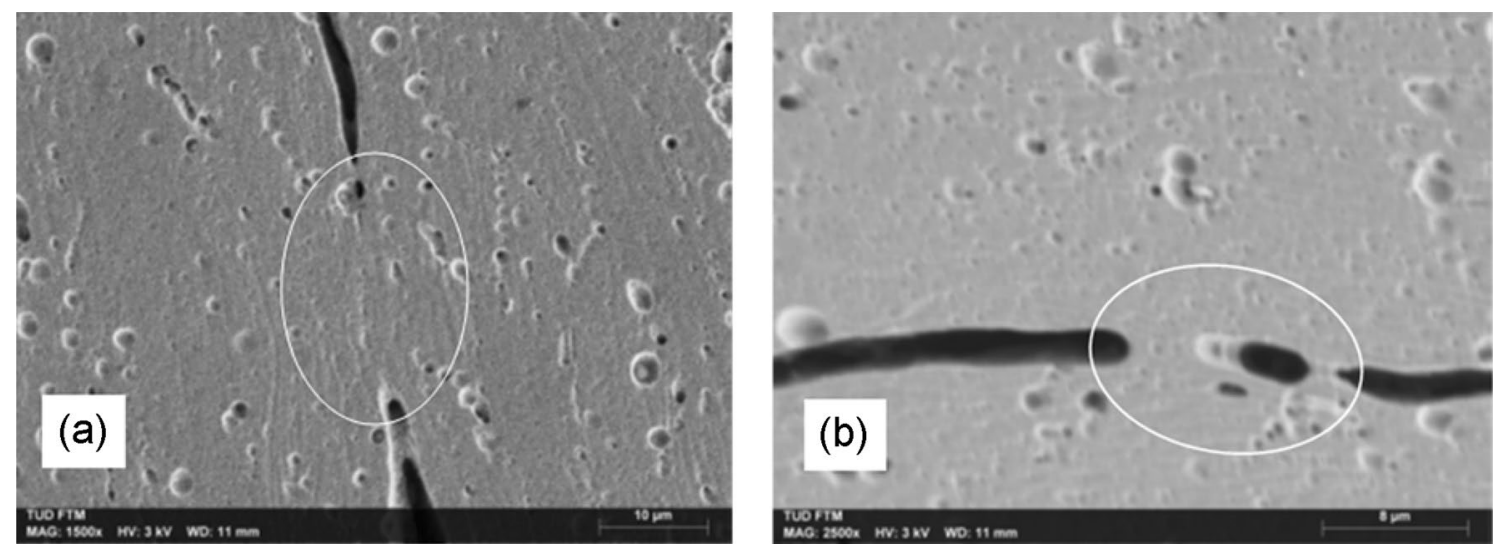

Fig. 9 Metallic micro-contacts at neck (a) and at bottom area (b) at specimen of series 3 
In the scanning electron micrographs in Fig. 9, metallic micro-contacts can be detected in the neck (Fig. 9a) and bottom (Fig. 9b) areas.

These metallic micro-contacts are retained even after precipitation hardening from the joining state $\mathrm{T} 4$ to the state T6. If the interaction of the processes of surface enlargement, relative movement and friction is known, the clinching process can be used to specifically generate such metallic micro-contacts. Sahin presents this effect of material-closure in [28] against the background of cold pressure welding of aluminum and copper materials and Ozel in [29] for Aluminum materials, when deformation ratios greater than $70 \%$ are present. This is advantageous, for example, for contacting electrical conductors. The following processes take place during clinching:

- Surface enlargement,

- Breaking of the natural oxide layer and thus the formation of metallic blank contact surfaces,

- Relative movement of the joining partners to each other,

- Cleaning effect of surfaces sliding on each other,

- Surface pressure between the joining partners.

These effects can generate metallic micro-contacts in the clinching joints via the tool parameters or a surface pre-processing. Due to the increase in surface area and the relative movements occurring during the joining process, these metallic micro-contacts mainly occur in the neck and bottom areas.

\section{Discussion}

Based on the results obtained from mechanical testing and electrical testing, as well as the energy applied during the joining process, the following flow chart (Fig. 10) can be created for the design of a clinching process.

The path from left to right starts with the characterization of the joining partners. This represents the previous procedure for the production of clinched joints, which is also described in [15]. The joining partners and the tools, previously selected empirically or via a process simulation generate a clinched joint (Fig. 10/path 1). The form-closure is generated by various parameters, e.g., tool geometries, friction conditions or surface layers. If a head tensile load occurs, the undercut represents this binding mechanism. If a shear load occurs between joining partners due to an external load, the penetration depth is added to this binding mechanism. In the case of a peel load, the influence of the undercut between joining partners dominates. The binding mechanism force-closure is represented by path 2 in Fig. 10 . The magnitude of the force-closure component depends on the spring-back effect of the component materials and the friction between the joining partners that occurs. A comparison of series 1 and 2 shows a changed proportion of the force-closure component of 33\% (Fig. 7) with almost identical parameters for the form-closure component. This increased force-closure component requires an increased energy input of $13 \%$ (Table 1).

In addition to paths 1 and 2, path 3 (Fig. 10) is included in the investigations for series 3 . The changed surface condition before joining initially causes increased friction, which is reflected in a higher joining force (Fig. 3). The slightly

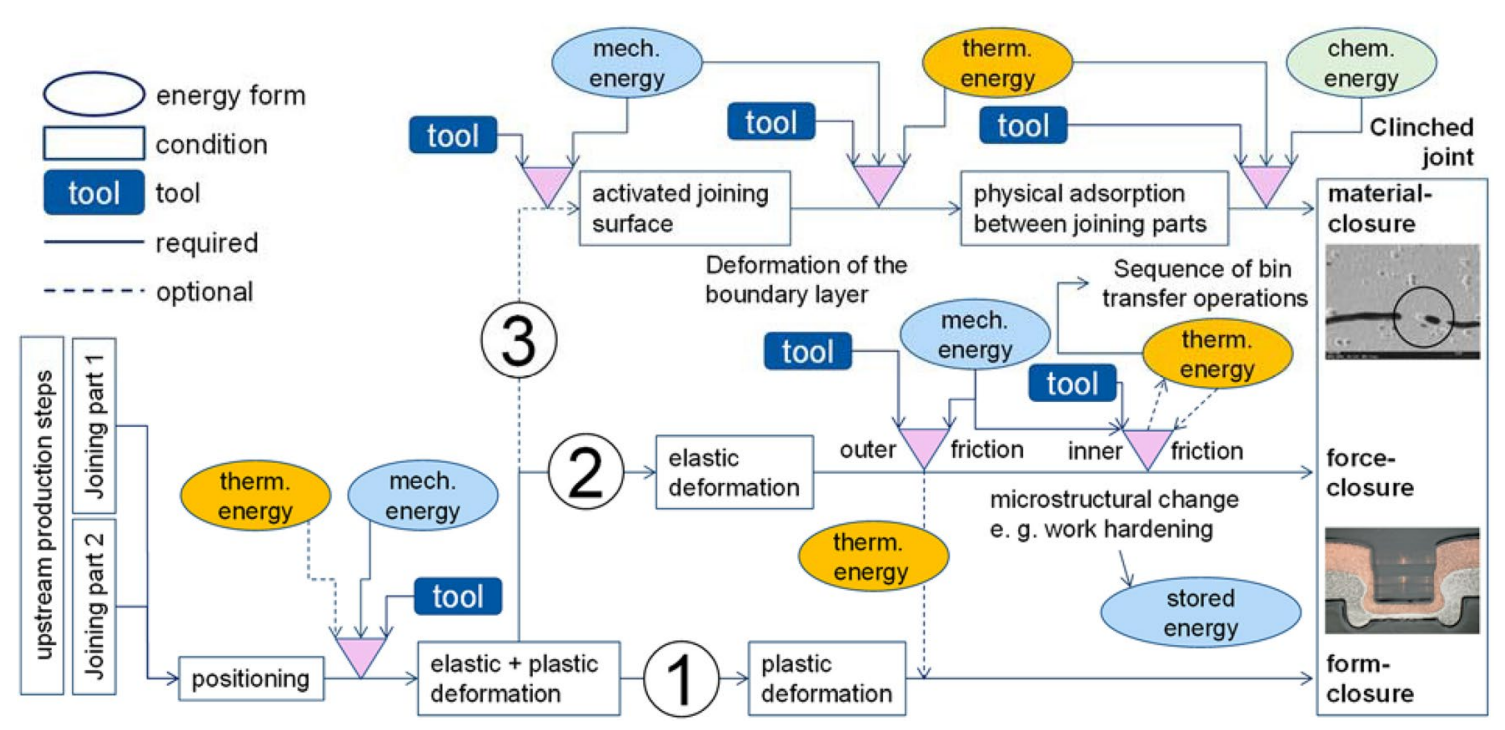

Fig. 10 Flow chart for designing a clinched joint 
increased energy input of series 3 of $1 \%$, compared to series 2 , due to the changed surface condition causes, an increased quasi-static shear load of $31 \%$ (Fig. 6), a significant increase of the torsional moment up to 527\% (Fig. 7) and a reduction of the electrical resistance of $48 \%$ (Fig. 8). The increased torsional moment can be attributed to an increased forceclosure component, whereby a material closure could also promote this torsional moment.

When designing clinched joints according to the necessary binding mechanisms and required properties for the respective load, e.g., mechanical or corrosive stress or electrical conductivity, this flow chart can be read in the opposite direction. The achievement of these required binding mechanisms determines the geometry of the clinched joint, the required tools and the required process parameters. The energy to be applied can differ in its forms and amounts. The various forms of energy are introduced into the parts to be joined via tools. The possible conversion of one form of energy into another is also taken into account. In the simplest case, the mechanical energy leads to a sufficiently large elastic-plastic deformation and thus to a form-closure and force-closure component between the joining partners. Optionally, an additional material-closure can also be produced if the appropriate energy is supplied [7]. The individual binding mechanisms and their proportions can be adapted to the subsequent life cycle in accordance with the types of loading present.

\section{Conclusions}

The tests carried out and the results obtained confirm the thesis that properties of clinched joints are determined by the binding mechanisms form-closure, force-closure and material-closure.

It is possible to detect and quantify different components of the binding mechanisms via mechanical and electrical testing.

Based on the description of a clinched joint by formclosure, force-closure and material-closure, the properties required for its loading can be determined by varying the required binding mechanisms.

The same geometrical parameters for neck thickness and undercut can lead to considerable differences in the mechanical stress state and thus in the force-closure component even when the same die and different punch geometries are used. That means, that the selection of tools can be done by knowing the transmissible load as an optimum version.

Activation of the surface by removing impurities leads to a significant increase in force-closure component and generation of a material-closure component with the same tool parameters and almost the same energy input. This makes it possible to use clinched joints designed in this way for contacting electrical conductors.

A further conclusion opens up the perspective of an energetically reduced clinching process. Against the background of the load type and load level specified by the design, the required energy input can be reduced by means of tool selection and process parameters. In hybrid joining processes, e.g. clinching and adhesive bonding, the primary strength properties of hybrid joined components are based on the property profile of the adhesive. In this case, the design of the clinched joints could not be based on maximum strength properties, but on the lowest total energy input in each case.

Acknowledgements "Funded by the Deutsche Forschungsgemeinschaft (DFG, German Research Foundation)-TRR 285-Project-ID 418701707".

Funding Open Access funding enabled and organized by Projekt DEAL.

Open Access This article is licensed under a Creative Commons Attribution 4.0 International License, which permits use, sharing, adaptation, distribution and reproduction in any medium or format, as long as you give appropriate credit to the original author(s) and the source, provide a link to the Creative Commons licence, and indicate if changes were made. The images or other third party material in this article are included in the article's Creative Commons licence, unless indicated otherwise in a credit line to the material. If material is not included in the article's Creative Commons licence and your intended use is not permitted by statutory regulation or exceeds the permitted use, you will need to obtain permission directly from the copyright holder. To view a copy of this licence, visit http://creativecommons.org/licenses/by/4.0/.

\section{References}

1. Zwicker MFR, Moghadam M, Zhang W, Nielsen CV (2020) Automotive battery pack manufacturing - a review of battery to tab joining. J Adv Join Process. https://doi.org/10.1016/j.jajp.2020. 100017

2. Das A, Li D, Williams D, Greenwood D (2018) Joining technologies for automotive battery systems manufacturing. World Electr Veh J. https://doi.org/10.3390/wevj9020022

3. DVS Media GmbH (2009) DVS-Merkblätter und Richtlinien Mechanisches Fügen, DVS-Fachbücher, vol 153. DVS Media GmbH, Düsseldorf (ISBN 978-3-87155-230-4)

4. Ewenz L, Kalich J, Zimmermann M, Füssel U (2021) Effect of different tool geometries on the mechanical properties of Al-Al clinch joints. Key Eng Mater 883:65-72. https://doi.org/10.4028/ www.scientific.net/kem.883.65

5. Groche P, Wohletz S, Brenneis M, Pabst C, Resch F (2014) Joining by forming - a review on joint mechanisms, applications and future trends. J Mater Process Technol 214:1972-1994. https:// doi.org/10.1016/j.jmatprotec.2013.12.022

6. Salamati M, Soltanpour M, Fazli A, Zajkani A (2019) Processing and tooling considerations in joining by forming technologies; part A-mechanical joining. Int J Adv Manuf Technol 101:261315. https://doi.org/10.1007/s00170-018-2823-y 
7. Riedel F (1997) Eigenschaftsverbesserung von Durchsetzfügeverbindungen durch die Kombination mit Stoffschluss. Shaker Verlag GmbH, Düren

8. Füssel U, Kalich J, Großmann K, Schlegel S, Schmid J (2014) Elektrisches Eigenschaftsprofil umformtechnischer Fügeverbindungen, EFB-Forschungsbericht Nr. 389. European Research Association for Sheet Metal Working, Hannover (ISBN: 978-3-86776-432-2)

9. Tenorio MB, Lajarin SF, Gipiela ML, Marcondes PVP (2019) The influence of tool geometry and process parameters on joined sheets by clinching. J Braz Soc Mech Sci Eng 41:67. https://doi. org/10.1007/s40430-018-1539-0

10. He X (2017) Clinching for sheet materials. Sci Technol Adv Mater 18(1):381-405

11. Jónás S, Tisza M (2020) Effect of the friction coefficient on clinch joints. Int J Eng Manag Sci 5(2):86-90

12. Füssel U, Kalich J, Großmann S, Schlegel S, Ramonat A (2019) Optimierung Umformtechnischer Fügeverfahren zur Kontaktierung elektrischer Leiter, EFB Forschungsbericht Nr. 506. European Research Association for Sheet Metal Working, Hannover (ISBN-13: 978-3867765596)

13. Steinfelder Ch, Kalich J, Brosius A, Füssel U (2021) Numerical and experimental investigation of the transmission moment of clinching points. IOP Conf Ser Mater Sci Eng 1157:012003. https://doi.org/10.1088/1757899X/1157/1/012003

14. Abe Y, Kato T, Mori K (2007) Joining of aluminium alloy and mild steel sheets using mechanical clinching. Mater Sci Forum 561-565:1043-1046

15. Lee C-J, Kim JY, Lee SK, Ko DC, Kim BM (2010) Design of mechanical clinching tools for joining of aluminium alloy sheets. Mater Des 31:1854-1861. https://doi.org/10.1016/j.matdes.2009. 10.064

16. Gibmeier J, Lin R, Odén M, Scholtes B (2002) Residual stress distribution around clinched joints. Mater Sci Forum 404-407:617-622

17. Kalich J, Füssel U (2021) Influence of the production process on the binding mechanism of clinched aluminum steel mixed compounds. J Manuf Mater Process 5:105. https://doi.org/10.3390/ jmmp5040105

18. Altenpohl D (1965) Aluminium und Aluminiumlegierungen, 1st edn. Springer, Berlin (ISBN 978-3-662-30246-0)
19. (2019) Datasheet automotive. Novelis Advanz ${ }^{\mathrm{TM}} 6 \mathrm{~F}$ - 170 . Novelis Global Automotive. Novelis AG: Kuesnacht

20. DIN EN ISO 14273:2016, Widerstandsschweißen-Zerstörende Prüfung von Schweißverbindungen-Probenmaße und Verfahren für die Scherzugprüfung an Widerstandspunkt-, Rollennaht- und Buckelschweißungen mit geprägten Buckeln (ISO 14273:2016); Deutsche Fassung

21. Slade PG (ed) (2014) Electrical contacts: principles and applications, 2nd edn. CRC Press, Boca Raton (ISBN 978-1-4398-8131-)

22. Kogut L, Komvopoulos K (2003) Electrical contact resistance theory for conductive rough surfaces. J Appl Phys 94:3153-3162. https://doi.org/10.1063/1.1592628

23. Kogut L (2005) Electrical performance of contaminated rough surfaces in contact. J Appl Phys 97:103723. https://doi.org/10. $1063 / 1.1914954$

24. Holm R (2000) Electric contacts-theory and applications. Springer, Berlin (ISBN 3-540-03875-2)

25. Zhai C, Hanaor D, Proust G, Brassart L, Gan Y (2016) Interfacial electro-mechanical behaviour at rough surfaces. Extreme Mech Lett 9:422-429

26. Zhang J, Ma M, Shen F, Yi D, Wang B (2017) Influence of deformation and annealing on electrical conductivity, mechanical properties and texture of Al-Mg-Si alloy cables. Mater Sci Eng A 2018(710):27-37. https://doi.org/10.1016/j.msea.2017.10.065

27. Jiang T, Liu ZX, Wang PC (2015) Quality inspection of clinched joints of steel and aluminum. Int J Adv Manuf Technol 76:13931402. https://doi.org/10.1007/s00170-014-6362-x

28. Sahin M, Misirli C (2012) Properties of cold pressure welded aluminium and copper sheets. AMR 463-464:244-248. https:// doi.org/10.4028/www.scientific.net/amr.463-464.244

29. Ozel K, Sahin M, Akdoğan A (2008) Mechanical and metallurgical properties of aluminium and copper sheets joined by cold pressure welding. Strojniški vestnik J Mech Eng 54:796-806

Publisher's Note Springer Nature remains neutral with regard to jurisdictional claims in published maps and institutional affiliations. 